\title{
Населення голих амеб на межі зони «мох - грунт» у лісових екосистемах України
}

\section{Марина Пацюк}

Житомирський державний університет імені Івана Франка, Житомир, Україна

Адреса для листування: kostivna@ukr.net

Отримано: 20.05.20; прийнято до друку: 28.08.20; опубліковано: 02.09.20

Резюме. У досліджених мікробіотопах (мох, межа «мох - грунт», грунт) України нами знайдено 17 видів голих амеб. Це такі види: Vahlkampfia sp. (1), Vahlkampfia sp. (2), Willaertia sp., Deuteramoeba mycophaga (Pussard, Alabouvette \& Pons, 1980) Page, 1988, Saccamoeba stagnicola Page, 1974, Hartmannella vermiformis Page, 1967, Korotnevella sp., Vexillifera sp., Vannella sp., Ripella platypodia Glaeser, 1912, Cochliopodium sp., Mayorella cantabrigiensis Page, 1983, Mayorella sp., Thecamoeba striata (Penard, 1890) Schaeffer, 1926, Stenamoeba stenopodia (Page, 1969) Smirnov et al., 2007, Acanthamoeba sp. (1), Filamoeba nolandi Page, 1967. На межі мікробіотопів «мох - грунт» не формується специфічний варіант населення голих амеб і не спостерігається збільшення його видового багатства, а залишаються види, характерні для одного з сусідніх мікробіотопів. Для грунтової фауни характерні амеби Willaertia sp., D. mycophaga, Korotnevella sp., M. cantabrigiensis, F. nolandi. Не формується специфічний склад морофтипів голих амеб на межі «мох - грунт» і сусідні мікробіотопи за складом морфотипів подібні між собою. Амеба політактичного морфотипу надає перевагу грунту, язикоподібного та майорельного - грунту та межі «мох - грунт», що має пристосувальний характер до умов середовища.

Ключові слова: голі амеби, морфотипи, мікробіотопи, Україна.

\section{The Communities of Naked Amoebas on the Border of the Zone "Moss - Soil" in the Forest Ecosystems of Ukraine}

\section{Maryna Patsyuk}

Zhytomyr Ivan Franko State University, Zhytomyr, Ukraine Address for correspondence:e-mail: kostivna@ukr.net

\begin{abstract}
In microbiotopes of Ukraine we found 17 species of naked amoebae (moss, border "moss - soil", soil). This species are: Vahlkampfia sp. (1), Vahlkampfia sp. (2), Willaertia sp., Deuteramoeba mycophaga (Pussard, Alabouvette \& Pons, 1980) Page, 1988, Saccamoeba stagnicola Page, 1974, Hartmannella vermiformis Page, 1967, Korotnevella sp., Vexillifera sp., Vannella sp., Ripella platypodia Glaeser, 1912, Cochliopodium sp., Mayorella cantabrigiensis Page, 1983, Mayorella sp., Thecamoeba striata (Penard, 1890) Schaeffer, 1926, Stenamoeba stenopodia (Page, 1969) Smirnov et al., 2007, Acanthamoeba sp. (1), Filamoeba nolandi Page, 1967. On the border of biotopes "moss - soil", a specific variant of the population of naked amoebas does not form and an increase in its species composition is not observed, but those species that are characteristic of one of the neighboring microbiotopes remain. The soil fauna is characterized by amoeba Willaertia sp., D. mycophaga, Korotnevella sp., M. cantabrigiensis, F. nolandi. The specific composition of morphotypes of naked amoebas is not formed on the "moss - soil" boundary and neighboring microbiotopes are similar in composition to each other. The amoeba of politactic morphotype prefers soil, lingulate and mayorellian - soil and the border "moss - soil".
\end{abstract}

Key words: naked amoebas, morphotypes, microbiotopes, Ukraine. 


\section{ВСТУП}

Голі амеби - одна 3 найпоширеніших груп найпростіших у водному та грунтовому середовищах. Екологія цих протистів мало вивчена. Більшість досліджень стосується вивченню їх філогенії [33-35]. У зарубіжній літературі є матеріали щодо поширення голих амеб поряд 3 іншими групами найпростіших (черепашковими амебами, гетеротрофними джгутиконосцями, інфузоріями) у водоймах і грунтах [14-17; 32]. Попередні наші дослідження стосувались лише прісноводної [2-11; 19-29] та частково грунтової фауни амеб $[30,31]$. Так, за нашими даними у водоймах України ідентифіковано 47 видів голих амеб і на їх поширення впливають температура, концентрація розчинених у воді кисню та органічних речовин (за перманганатною окислюваністю) [2-11; 19-29]. У грунтах степової, лісостепової та зони мішаних лісів України нами знайдено 24 види амеб і на їх розподіл впливають температура, кислотність та вологість грунтів [30, 31]. Цікавим питанням залишається вивчення крайових ефектів просторового розподілу населення безхребетних. Відомо, що існує ефект екотону, характерний для черепашкових амеб на рівні мох - лишайник, мох - грунт. Збільшення видового багатства черепашкових амеб спостерігається в крайових зонах, зменшення по мірі змішення сусідніх екотонів [1; 12-13]. Такі дані щодо голих амеб відсутні. Тому ми спробували 3'ясувати видовий склад i поширення голих амеб та їх морфотипів на межі зони «мох - грунт» у лісових зонах України.

Мета та завдання дослідження: вивчити особливості населення голих амеб на межі зони «мох - грунт» у лісових зонах України. Ця робота $\epsilon$ продовженням вивчення видового складу голих амеб та їх морфотипів у мохах $\mathrm{i}$ грунтах України.

\section{МАТЕРІАЛ І МЕТОДИ ДОСЛІДЖЕНЬ}

Матеріал був відібраний у серпні 2019 року. Всього було вивчено три площадки. Перша розміщувалась у сосновому лісі лишайниковому (Рівненська область, Сарненський район). Досліджувана площадка розпочиналась на ділянці, яка утворена мохом (Sphagnum sp.) і закінчувалась на слабо підзолистому, глинисто-піщаному грунті 3 добре вираженою підстилкою до 4 см (опад хвої). Дві інші площадки знаходились у лісових екосистемах Житомирської області. Друга площадка розміщувалась у дубовому лісі ліщиново-мікелієво-сосновому (Житомирська область, Тригірське лісництво). Починалась на ділянці, яка вкрита мохом Sphagnum sp. i закінчувалась на сірому лісовому грунті з добре розвиненою підстилкою. Третя площадка була розміщена у межах грабово-дубово-сосновому лісі ліщиново-трясучкоподібноосоковому (Житомирська область, Житомирський ЛГ). Починалась 3 ділянки, вкритої мохом Sphagnum sp. і закінчувалась на сірому лісовому грунті 3 добре розвиненою підстилкою, представленою листяним опадом. Протяжність кожної площадки складала до 40 см. На кожній 3 них було відібрано по 5 проб (перші дві в межах мохової ділянки (M1, M2), третя на межі мохової та грунтової ділянок $(\mathrm{M} / Г \mathrm{p})$, останні дві - на грунтовій ділянці (Гр1, Гр2)) на відстані 8 см одна від одної [1].

5 г досліджуваного субстрату розміщували в закриту колбу на 100 мл, заливали дистильованою водою та залишали на добу для розмокання субстрату. Згодом суміш струшували впродовж 10 хвилин [1]. 5 мл досліджуваного розчину рівномірно розподіляли в чашки Петрі з непоживним агарагаром. Розмноження амеб проводили за методикою Пейджа [18].

\section{РЕЗУЛЬТАТИ ДОСЛІДЖЕННЯ}

В результаті дослідження було ідентифіковано 17 видів голих амеб (табл. 1). Найбільшу кількість видів знайдено в першій площадці (сосновий ліс лишайниковий, Сарненський район, Рівненська область) - 15 видів. Це види: Vahlkampfia sp. (1), Vahlkampfia sp. (2), Deuteramoeba mycophaga (Pussard, Alabouvette \& Pons, 1980) Page, 1988,

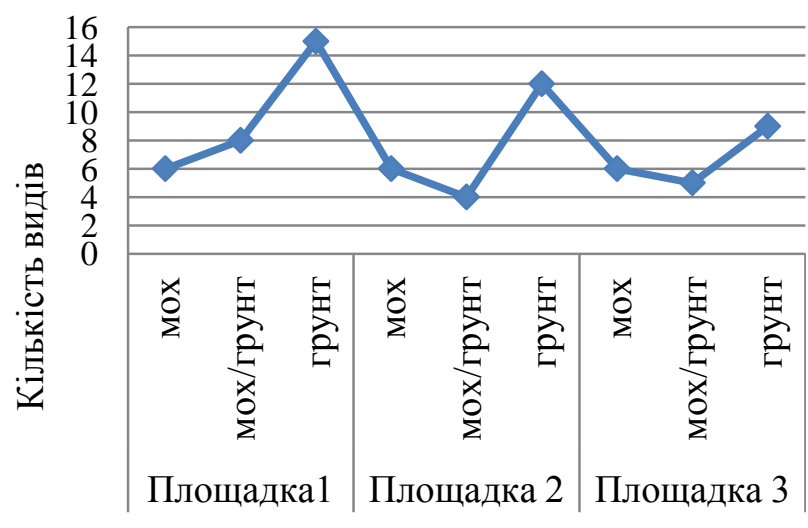

Рис. 1. Розподіл голих амеб у мікробіотопах лісових екосистем України 
Поширення голих амеб на межі зон «мох - грунт» («+» - вид є, «-»- виду немає)

\begin{tabular}{|c|c|c|c|c|c|c|c|c|c|c|c|c|c|c|c|c|}
\hline \multirow[b]{2}{*}{$\begin{array}{l}\text { № } \\
\text { П/ח }\end{array}$} & \multirow[b]{2}{*}{ Види амеб } & \multicolumn{5}{|c|}{ Площадка 1} & \multicolumn{5}{|c|}{ Площадка 2} & \multicolumn{5}{|c|}{ Площадка 3} \\
\hline & & $\begin{array}{l}\mathrm{M} \\
1\end{array}$ & $\begin{array}{l}\mathrm{M} \\
2\end{array}$ & $\begin{array}{l}\mathrm{M} / \\
\Gamma \mathrm{p}\end{array}$ & \begin{tabular}{|c|}
$\Gamma$ \\
p1
\end{tabular} & $\begin{array}{c}\Gamma \mathrm{p} \\
2\end{array}$ & $\begin{array}{c}\mathrm{M} \\
1\end{array}$ & $\begin{array}{l}M \\
2\end{array}$ & $\begin{array}{l}\mathrm{M} / \\
\Gamma \mathrm{p}\end{array}$ & $\begin{array}{c}\Gamma \mathrm{p} \\
1\end{array}$ & $\begin{array}{c}\Gamma \mathrm{p} \\
2\end{array}$ & $\begin{array}{c}\mathrm{M} \\
1\end{array}$ & $\begin{array}{c}M \\
2\end{array}$ & $\begin{array}{l}\mathrm{M} / \\
\Gamma \mathrm{p}\end{array}$ & $\begin{array}{c}\Gamma \mathrm{p} \\
1\end{array}$ & $\begin{array}{c}\Gamma \mathrm{p} \\
2\end{array}$ \\
\hline 1. & Vahlkampfia sp. (1) & - & - & + & + & + & + & + & + & + & + & + & + & + & + & + \\
\hline 2. & Vahlkampfia sp. (2) & + & + & + & + & + & + & + & + & + & + & - & - & - & - & - \\
\hline 3. & Willaertia sp. & - & - & - & - & - & - & - & - & + & + & - & - & - & + & + \\
\hline 4. & $\begin{array}{c}\text { Deuteramoeba } \\
\text { mycophaga (Pussard, } \\
\text { Alabouvette\& Pons, } \\
\text { 1980) Page, } 1988\end{array}$ & - & - & - & + & + & - & - & - & + & + & - & - & - & + & + \\
\hline 5. & $\begin{array}{c}\text { Saccamoeba stagnicola } \\
\text { Page, } 1974\end{array}$ & - & - & - & + & + & - & + & - & + & + & - & - & - & + & + \\
\hline 6. & $\begin{array}{c}\text { Hartmannella } \\
\text { vermiformis Page, } 1967\end{array}$ & + & + & + & + & + & - & - & - & - & - & - & - & - & - & - \\
\hline 7. & Korotnevella sp. & - & - & - & + & + & - & - & - & - & - & - & - & - & - & - \\
\hline 8. & Vexillifera & - & - & - & + & + & + & + & + & + & + & + & + & + & + & + \\
\hline 9. & Vannella sp. & + & + & + & + & + & + & + & + & + & + & + & + & + & + & + \\
\hline 10. & $\begin{array}{c}\text { Ripella platypodia } \\
\text { Glaeser, } 1912 \\
\end{array}$ & - & - & + & + & - & - & - & - & + & + & - & - & - & - & - \\
\hline 11. & Cochliopodium sp. & 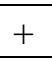 & + & - & + & + & - & - & - & + & + & + & + & + & + & + \\
\hline 12. & $\begin{array}{c}\text { Mayorella } \\
\text { cantabrigiensis Page, } \\
1983\end{array}$ & - & - & - & + & + & - & - & - & - & - & - & - & - & - & - \\
\hline 13. & Mayorella sp. & - & - & - & - & - & + & + & - & + & + & + & + & - & + & + \\
\hline 14. & $\begin{array}{l}\text { Thecamoeba striata } \\
\text { (Penard, 1890) } \\
\text { Schaeffer, 1926 }\end{array}$ & + & + & + & + & + & - & - & - & + & + & + & + & + & + & + \\
\hline 15. & $\begin{array}{c}\text { Stenamoeba stenopodia } \\
\text { (Page, 1969) Smirnov et } \\
\text { al., } 2007\end{array}$ & - & - & + & + & + & - & - & - & + & + & - & - & - & - & - \\
\hline 16. & Acanthamoeba sp. (1) & + & + & + & + & + & - & - & - & - & - & - & - & - & - & - \\
\hline 17. & $\begin{array}{l}\text { Filamoeba nolandi } \\
\text { Page, } 1967\end{array}$ & - & - & - & + & + & - & - & - & - & - & - & - & - & - & - \\
\hline \multirow{2}{*}{\multicolumn{2}{|c|}{ Всього }} & 6 & 6 & 8 & 15 & 14 & 5 & 6 & 4 & 12 & 12 & 6 & 6 & 5 & 9 & 9 \\
\hline & & \multicolumn{5}{|c|}{15} & \multicolumn{5}{|c|}{12} & \multicolumn{5}{|c|}{9} \\
\hline
\end{tabular}

Saccamoeba stagnicola Page, 1974, Hartmannella vermiformis Page, 1967, Korotnevella sp., Vexillifera sp., Vannella sp., Ripella platypodia Glaeser, 1912, Cochliopodium sp., Mayorella cantabrigiensis Page, 1983, Thecamoeba striata (Penard, 1890) Schaeffer, 1926, Stenamoeba stenopodia (Page, 1969) Smirnov et al., 2007, Acanthamoeba sp. (1), Filamoeba nolandi Page, 1967. Найменша кількість видів характерна для третьої площадки (грабово-дубово-сосновий ліс ліщиново-трясучкоподібноосоковий, Житомирська область, Житомирський ЛГ) - 9 видів (табл. 1). Це види: Vahlkampfia sp. (1), Willaertia sp., D. mycophaga, S. stagnicola, Vexillifera sp., Vannella sp., Cochliopodium sp., Mayorella sp.,
T. striata. $\mathrm{У}$ другій площадці (дубовий ліс ліщиново-мікелієво-осоковий, Житомирська область, Тригірське лісництво) виявлено 12 видів амеб. Це види: Vahlkampfia sp. (1), Vahlkampfia sp. (2), Willaertia sp., D. mycophaga, $S$. stagnicola, Vexillifera sp., Vannella sp., $R$. platypodia, Cochliopodium sp., Mayorella sp., T. striata, S. stenopodia.

У всіх трьох площадках трапляються амеби Vahlkampfia sp. (1), D. mycophaga, S. stagnicola, Vexillifera sp., Vannella sp., Cochliopodium sp., T. striata, що складає 41\% від загальної кількості знайдених видів.

Для мікробіотопів (мох, межа «мох - грунт», грунт) соснового лісу лишайникового 
Поширення морфотипів голих амеб на межі зон «мох - грунт» («+»- морфотип с, «-»- морфотипу немас)

\begin{tabular}{|c|c|c|c|c|c|c|c|c|c|c|c|c|c|c|c|c|}
\hline \multirow[b]{2}{*}{$\begin{array}{c}\text { № } \\
\Pi / \Pi\end{array}$} & \multirow[b]{2}{*}{ Морфотипи амеб } & \multicolumn{5}{|c|}{ Площадка 1} & \multicolumn{5}{|c|}{ Площадка 2} & \multicolumn{5}{|c|}{ Площадка 3} \\
\hline & & $\begin{array}{c}M \\
1\end{array}$ & $\begin{array}{c}M \\
2\end{array}$ & $\begin{array}{l}\mathrm{M} / \\
\Gamma \mathrm{p}\end{array}$ & $\begin{array}{c}\Gamma \mathrm{p} \\
1\end{array}$ & $\begin{array}{c}\Gamma \mathrm{p} \\
2\end{array}$ & $\begin{array}{c}M \\
1\end{array}$ & $\begin{array}{l}M \\
2\end{array}$ & $\begin{array}{l}\mathrm{M} / \\
\Gamma \mathrm{p}\end{array}$ & $\begin{array}{c}\Gamma \mathrm{p} \\
1\end{array}$ & $\begin{array}{c}\Gamma \mathrm{p} \\
2\end{array}$ & $\begin{array}{c}M \\
1\end{array}$ & $\begin{array}{l}M \\
2\end{array}$ & $\begin{array}{l}\mathrm{M} / \\
\Gamma \mathrm{p}\end{array}$ & $\begin{array}{c}\Gamma \mathrm{p} \\
1\end{array}$ & $\begin{array}{c}\Gamma p \\
2\end{array}$ \\
\hline 1. & Еруптивний & + & + & + & + & + & + & + & + & + & + & + & + & + & + & + \\
\hline 2. & Політактичний & - & - & - & + & + & - & - & - & + & + & - & - & - & + & + \\
\hline 3. & Моноподіальний & + & + & + & + & + & - & + & - & + & + & - & - & - & + & + \\
\hline 4. & Стріатний & + & + & + & + & + & - & - & - & + & + & + & + & + & + & + \\
\hline 5. & Віялоподібний & + & + & + & + & + & + & + & + & + & + & + & + & + & + & + \\
\hline 6. & Язикоподібний & - & - & + & + & + & - & - & - & + & + & - & - & - & - & - \\
\hline 7. & Майорельний & - & - & - & + & + & + & + & - & + & + & + & + & - & + & + \\
\hline 8. & Дактилоподіальний & - & - & - & + & + & + & + & + & + & + & + & + & + & + & + \\
\hline 9. & Лінзоподібний & + & + & - & + & + & - & - & - & + & + & + & + & + & + & + \\
\hline 10. & Акантоподіальний & + & + & + & + & + & - & - & - & - & - & - & - & - & - & - \\
\hline \multirow{2}{*}{\multicolumn{2}{|c|}{ Всього }} & 6 & 6 & 6 & 10 & 10 & 4 & 5 & 3 & 9 & 9 & 6 & 6 & 5 & 8 & 8 \\
\hline & & \multicolumn{5}{|c|}{10} & & \multicolumn{5}{|c|}{8} \\
\hline
\end{tabular}

(Сарненський район, Рівненська область) характерні 5 видів амеб, які не траплялись у площадках 2 і 3: H. vermiformis, Korotnevella sp., M. cantabrigiensis, Acanthamoeba sp. (1), F. nolandi. Для мікробіотопів площадок 1 і 2 спільним є: Vahlkampfia sp. (2), R. platypodia, $S$. stenopodia, для площадок 2 і 3 - Willaertia sp., Mayorella sp.

Розглянемо особливості населення амеб у кожній площадці (табл. 1). У першій площадці в усіх мікробіотопах траплялись Vahlkampfia sp. (2), $H$. vermiformis, Vannella sp., T. striata, Acanthamoeba sp. (1), що складає $33 \%$ від 15 ідентифікованих видів у мікробіотопах соснового лісу лишайникового Сарненського району Рівненської області. Видове багатство в мохах -6 видів, у грунтах - 14-15 видів, на межі «мох - грунт» - 8 видів. Специфічними в цій площадці $€$ види $D$. mycophaga, $S$. stagnicola, Vexillifera sp., Korotnevella sp., M. cantabrigiensis, $F$. nolandi, які надають перевагу лише грунтам. Ці види відсутні в мохах і на межі «мох - грунт». Vahlkampfia sp. (1), $R$. platypodia та $S$. stenopodia траплялись як у грунтах, так і на межі «мох - грунт».

У другій площадці (дубовий ліс ліщиновомікелієво-осоковий, Житомирська область, Тригірське лісництво) у мохах трапляються 5-6 видів голих амеб, на межі «мох - грунт» -4 види, у грунтах - 12 видів (табл. 1). Willaertia sp., D. mycophaga, R. platypodia, S. stenopodia, Cochliopodium sp., T. striata трапляються лише в грунтах; у мохах і грунтах трапляються $S$. stagnicola, Mayorella sp., ці види відсутні на межі «мох - грунт». У всіх мікробіотопах трапляються види Vahlkampfia sp. (1), Vahlkampfia sp. (2), Vexillifera sp., Vannella sp.

У третій площадці (грабово-дубовососновий ліс ліщиново-трясучкоподібний, Житомирська область, Житомирський ЛГ) в усіх мікробіотопах трапляється 5 видів амеб: Vahlkampfia sp. (1), Vexillifera sp., Vannella sp., Cochliopodium sp., T. striata, що складає $56 \%$ від усіх знайдених у цій площадці видів амеб. Видове багатство в мохах - 6 видів, на межі «мох - грунт» - 5 видів, у грунтах -9 видів. Для грунтів характерні види D. mycophaga, Willaertia sp. Ці види відсутні в інших мікробіотопах третьої площадки. Mayorella sp. характерна для мохів і грунтів, відсутня на межі «мох - грунт».

Нами ідентифіковані амеби, які належать до 10 морфотипів (табл. 2): еруптивного (Vahlkampfia sp. (1), Vahlkampfia sp. (2), Willaertia sp.), політактичного (D. mycophaga), моноподіального (S. stagnicola, $H$. vermiformis), стріатного (T. striata), віялоподібного (Vannella sp., $R$. platypodia), язикоподібного (S. stenopodia), майорельного (M. cantabrigiensis, Mayorella sp.), дактилоподіального (Korotnevella sp., Vexillifera sp.), лінзоподібного (Cochliopodium sp.), акантоподіального (Acanthamoeba sp. (1), F. nolandi).

В усіх площадках трапляються амеби 9 морфотипів, амеба ящикоподібного морфотипу трапляється лише в першій та другій площадках, амеби акантоподіального морфотипу - в першій площадці (табл. 2). У 
Населення голих амеб на межі зони «мох - трунт» у лісових екосистемах України

всіх мікробіотопах (мох, межа «мох - грунт», грунт) трапляються амеби еруптивного, моноподіального, стріатного, віялоподібного, дактилоподіального, лінзоподібного, акантоподіального морфотипів, що складає 70\% від загальної кількості виявлених морфотипів амеб. Тоді як, амеба політактичного морфотипу трапляється лише в грунтах, язикоподібного - в грунтах і на межі «мох - грунт», майорельного - в мохах і грунтах.

Отже, наше дослідження показує, що на межі мікробіотопів «мох - грунт» не формується специфічний варіант населення голих амеб. У цьому мікробіотопі, як правило, наявні види, що характерні для сусідніх мікробіотопів. Тут не спостерігається збільшення видового багатства амеб, але можуть зникати види, які характерні для мохів і грунтів. Серед усіх знайдених амеб Willaertia sp., D. mycophaga, Korotnevella sp., $M$. cantabrigiensis, F. nolandi характерні лише для грунтової фауни. Загалом збільшення видового багатства амеб у грунтах пов'язано з умовами грунту: температурою, кислотністю, вологістю, що аналізується в наших попередніх дослідженнях [30, 31]. Не формується специфічний склад і морофтипів голих амеб на межі «мох - грунт» і сусідні мікробіотопи за складом морфотипів подібні між собою. Встановлено, що амеба політактичного морфотипу надає перевагу грунту, язикоподібного та майорельного - грунту та межі «мох - грунт», що також може мати пристосувальний характер до умов середовища.

\section{ЛITEPАТУРА}

1. Малышева, Е. А.; Мазей, Ю. А. Особенности структуры сообществ раковинных амеб в микроэкотонах «моховая подушка почвенная подстилка». Известия ПГПУ им. В. Г. Белинского; 2010, 17, 51-53.

2. Пацюк, М. К. Голі лобозні амеби (Lobosea, Gymnamoebia) деяких водойм околиць м. Радомишль. Наукові записки Тернопільського Національного педагогічного університету імені Володимира Гнатюка. Серія: Біологія. Спец. вип.: Гідроекологія; 2010, 2 (43), 390-395.

3. Пацюк, М. К. Виявлення голих амеб в озері Світязь. Наукові записки Тернопільського Начіонального педагогічного університету імені Володимира Гнатюка. Серія: Біологія; 2011, 3 (48), 27-30.

4. Пацюк, М. К. Таксономічний склад голих амеб Шацьких озер. Природа Західного Полісся та прилеглих територій: зб. наук. пр. Волин. нац. ун-т ім. Лесі Українки: Луцьк, 2012, 9, 177-180.

5. Пацюк, М.К. Голі амеби Шацьких озер.

Природа Західного Полісся та прилеглих
територій: зб. наук. пр. / за заг. ред. Ф. В. Зузука. Східноєвроп. нац. ун-т ім. Лесі Українки: Луцьк, 2014, 11, 239-243.

6. Пацюк, М. К. Сезонні зміни у видовому комплексі голих амеб у р. Кам'янка (м. Житомир). Вісник Запорізького національного університету. Біологічні науки; 2014, 2, 98-107.

7. Пацюк, М. К. Голі амеби фауни Київського Полісся. Наукові записки Тернопільського Національного педагогічного університету ім. Володимира Гнатюка. Серія: Біологія; 2014, 2 (59), 49-52.

8. Пацюк, М. К. Голі амеби фауни Рівненської області. Природа Західного Полісся та прилеглих територій: зб. наук. пр. / за заг. ред. Ф В. Зузука. Східноєвроп. нац. ун-т ім. Лесі Українки: Луцьк; 2015, 12, 154-157.

9. Пацюк, М. К. Просторовий розподіл голих амеб у донному грунті стоячої водойми поблизу м. Дніпро (Україна). Природа Західного Полісся та прилеглих територій: зб. наук. пр. / за заг. ред. Ф. В. Зузука. Східноєвроп. нац. ун-т ім. Лесі Українки: Луцьк; 2017, 7 (356), 128-133.

10. Пацюк, М. Видовий склад і поширення голих амеб (Tubulinea, Discosea, Heterolobosea) у водоймах Львівської області. Вісник Львівського унту. Серія біологічна; 2018, 79, 141-149.

11. Пацюк, М.; Уваєва, О. Прісноводні голі амеби (Tubulinea, Discosea, Heterolobosea) Закарпатської області та прилеглих територій (Україна). Науковий вісник Східноєвропейського національного університету імені Лесі Украӥнки. Серія: Біологічні науки; 2019, 3 (387), 109-115.

12. Balik, V. Testate amoebae communities (Protozoa, Rhizopoda) in a meadow - spurce forest mesoecotone. Biologia, Bratislava; 1996, 51, pp 117-124.

13. Balik, V. Testate amoebae communities (Protozoa, Rhizopoda) in two moss - soil microecotones. Biologia, Bratislava; 1996, 51, pp 125-133.

14. Brown, S.; Smirnov, A. V. Diversity of Gymnamoebae in Grassland Soil in Southern Scotland. Protistology; 2004, 3 (3), pp 191-195.

15. Brown, T. J.; Cursons, R. T. M.; Keys, E. A. Notes Amoebae from Antarctic Soil and Water. Applied and Environmental Microbiology; 1982, 44 (2), pp 491493.

16. Clarholm, M.; Bonkowski, M.; Griffiths, B. S. Protozoa and other Protista in Soil. In book: Modern Soil Microbiology, Publisher: Marcel Dekker, Amsterdam, Editors: van Elsas J. D., Trevors J. T., Wellington E. M. H.; 2007, pp 147-175.

17. Mrva, M. Diversity of Active Gymnamoebae (Rhizopoda, Gymnamoebia) in Mosses of the Malé Karpaty Mts (Slovakia). Ekologia Bratislava; 2005, 24, pp 51-58.

18. Page, F. C.; Siemensma, F. J. Nackte Rhizopoda und Heliozoea (Protozoenfauna Band 2). Gustav Fischer Verlag, Stuttgart, New York, 1991; pp 3-170.

19 Patcyuk, M. K. New Gymnamoebae species (Gymnamoebia) in the fauna of Ukraine. Vestnik zoologii; 2012, 46 (2), pp 105-111. 
20 Patsyuk, M. K.; Dovgal, I. V. Biotopic distribution of naked amoebes (Protista) in Ukrainian Polissya area. Vestnik zoologii; 2012, 46 (4), pp 355360 .

21 Patsyuk, M. K. Tolerance of Naked Amoebas to the Abiotic Factors of Water Environment. $V$ International Symposium of Ecologists of the Republic of Montenegro : the Book of Abstracts and Programme; 2013, p 137.

22 Patsyuk, M. K. Morphotypes in Naked Amoebas (Protista): Distribution in Water Bodies of Zhytomyr and Volyn Polissia (Ukraine) and Possible Ecological Significance. Vestnik zoologii; 2014, 48 (6), pp 547-552.

23 Patsyuk, M. K. Species of naked amoeba (Protista) new for the fauna of Ukraine. Vestnik zoologii; 2015, 49 (2), pp 451-456.

24 Patsyuk, M. K. New Finds of Naked Amoebae (Protista) in Water Reservoirs of Ukraine. Vestnik Zoologii; 2016, 50 (4), pp 291-300.

25 Patsyuk, M. K. Seasonal changes in the species composition of naked amoebas (Amoebina) of the Teterev river (the Town of Zhitomir). Hydrobiological Jornal; 2016, 52 (4), 55-62.

26 Patsyuk, M. K. Naked Amoebae of Ukrainian Polissya Fauna. Protistology; 2016, 10 (2), p 58.

27 Patsyuk, M. K. Parasitic Amoebae Found in Water Bodies of Ukraine. Experimental parasitology; 2017, 183, pp 81-84.
28 Patsyuk, M. K. Peculiarities of the Spatial Distribution of Naked Amoebas in Sandy Bottom Sediments of a Small River. Hydrobiological Jornal; 2018, 54 (5), pp 102-111.

29 Patsyuk, M. K.; Onyshchuk, I. P. Diversity and Distribution of Naked Amoebae in Water Bodies of Sumy Region (Ukraine). Vestnik Zoologii; 2019, 53 (3), pp 177-186.

30 Patsyuk, M. Changed species composition of naked amoebae in soils of forest-and-steppe zone of Ukraine. Acta Biologica; 2019, pp 57-64.

31 Patsyuk, M. Diversity of Naked Amoebae in Soils of Forest Areas of Zhytomyr Region (Ukraine). Zootaxa; 2020, pp 257-265.

32 Smirnov, A.; Brown, S. First isolation of a cyst-forming Vannella species, from soil - Vannella persistens n. sp. (Gymnamoebia, Vannellidae). Protistology; 2000, 1 (3), pp 120-123.

33 Smirnov, A.; Nassonova, E.; Chao, E.; Cavalier-Smith, T. Phylogeny, Evolution, and Taxonomy of Vannellid Amoebae. Protist; 2007, 158, pp 295-324.

34 Smirnov, A. Amoebas, Lobose. Encyclopedia of Microbiology. M. Schaechter (ed.). Elsevier: Oxford; 2008, pp 558-577.

35 Smirnov, A.; Nassonova, E.; Chao, E.; Cavalier-Smith, T. A Revised Classification of Naked Lobose Amoebae (Amoebozoa: Lobosa). Protist; 2011, 162, pp 545-570. 